\title{
Damp housing and adult health: results from a lifestyle study in Worcester, England
}

\author{
Claire N Packer, Sarah Stewart-Brown, Sarah E Fowle
}

\begin{abstract}
Study objective - To explore the relationship between damp housing and adult health using two separate measures of ill health and taking into account the confounding effects of health related lifestyles and social factors.

Design and setting - Analysis of responses gathered in a cross sectional, postal questionnaire survey of a randomly selected sample of 5347 residents of Worcester. Participants - Altogether 2353 people aged 16 to 64 years responded to the survey (adjusted response $52 \%$ ).

Results - Nine per cent of respondents lived in housing which they reported to be damp. Rates were highest among young women. People who lived in damp housing were more likely to report long standing illness, disability, or infirmity; the increased prevalence could not be attributed to any particular medical condition. Perceived ill health, as measured by the sleep, energy, and social isolation dimensions of the Nottingham Health Profile, was also more common in this group. These associations could not be explained by lifestyle factors; the relationship proved strongest among people in non-manual social classes living in owner occupied housing. The prevalence of ill health increased as the severity of dampness increased. Conclusion - Self reported damp housing and ill health in adults were strongly associated, most noticeably among people in non-manual social classes living in owner occupied housing. The association met many of the epidemiological criteria necessary for suggesting causality: alternative explanations are discussed.
\end{abstract}

( $f$ Epidemiol Community Health 1994;48:555-559)

Several studies ${ }^{1-5}$ have found an association between damp housing and ill health in children: the reported illnesses include respiratory symptoms, aches and pains, diarrhoea, "nerves", and headaches. A similar association in adults has been found less consistently, but a higher prevalence of general and respiratory symptoms has been reported. ${ }^{5-7}$ A survey of people living in the city of Worcester, which included questions on long standing illness and disability, health related lifestyles, housing conditions, and other social factors (Worcester City Health and Lifestyle Survey, 1990, unpublished) enabled us to investigate the relationship between damp housing and health in adults, taking into account a large number of potential confounding factors.

\section{Methods}

In 1990, in collaboration with Worcester and District Health Authority and Hereford and Worcester Family Health Services Authority, Worcester City Council funded a cross sectional postal health and lifestyle survey of city residents aged between 16 and 64 years. The survey was administered by the Department of Epidemiology and Public Health Medicine at the University of Bristol.

\section{QUESTIONNAIRE}

The questionnaire was developed from questions used and validated in other studies, including the General Household Survey (GHS), the Welsh Heart Health Survey, and the Nottingham Health Profile (NHP). It was very similar to a questionnaire that had been used in Avon County and Gloucestershire in 1988 and 1989 respectively.

People who responded positively to the GHS question, "Do you have any longstanding illness, disability or infirmity, anything that has troubled you over time or is likely to trouble you in the future?" were asked to identify the cause of their illness from a checklist of common conditions (table 1). This was compiled in 1987 following the pilot study for the Avon questionnaire (Avon County Health Survey, 1989, unpublished) in which respondents were invited to describe the cause of their long standing illness or disability as free text. Most reported causes fell into one of the 19 categories used in this survey (table 1).

The NHP is used to measure perceived ill health. ${ }^{8}$ It consists of two parts, the first of which contains 38 statements about problems in six dimensions of ill health to which respondents are asked to answer true or false. The six dimensions are: energy, pain, emotional reactions, social isolation, sleep, and physical mobility. In this study anyone who answered "true" to any statement in a dimension was classified as positive on that dimension. The second part contains seven questions about whether a respondent's present state of health affects their job of work, looking after the house, social life, home life, sex life, interests or hobbies, and holidays.

The questionnaire also included the question "how often do you suffer from these problems in your home; heavy condensation, damp, and mould?" There was a choice of responses for each problem: "never or hardly ever", "not 
Table 1 Checklist of the 19 categories used to describe the cause of long standing illness or disability

Arthritis

Back pain, including aches, lumbago, and disc problems

Raised blood pressure

Cancer

Chest problems, including asthma and bronchitis

Depression

Diabetes

Digestive problems

Hearing loss and ear problem

Heart disease, including angina

Problems resulting from an injury or accident

Kidney or bladder problems

Migraine or persistent headaches

Paralysis, stroke, epilepsy, or other neurological condition

Skin problems

Stress or anxiety

Varicose veins

Poor vision or eyes

Other problems

very often", "quite often", or "almost always". People who lived in housing which they described as suffering from damp or mould "quite often" or "almost always", or suffering from heavy condensation "almost always" were classified for the purposes of this study as living in damp housing. Other housing is referred to in this paper as dry housing.

The survey also included questions on smoking habits, alcohol consumption, exercise participation, height and weight, and housing tenure. Respondents were asked to classify the occupation of the main wage earner in their household, nominally the head of their household, into one of eight groups using examples of occupations falling into the Registrar General's social classes I and II combined, IIINM, IIIM, IV, and V, as well as never worked, and member of the armed forces or student.

The questionnaire was 20 pages long and was intended for a reading age of 10 years old.

\section{SAMPLE}

The questionnaire was mailed to a sample of one in 10, 16-64 year olds (5347) registered with the family health services authority who had a postcode within the city boundary during June 1990; a follow up letter was sent in July. Sample size calculations were made on a predicted $50 \%$ response rate with the ability to detect differences of greater than $5 \%$ with $95 \%$ confidence and a power of $90 \%$.

\section{STATISTICAL ANALYSIS}

Data were analysed using SPSS PC+ and Epi Info. Longstanding illness and NHP rates were adjusted for age, sex, and social class by direct standardisation. Statistical testing was carried out using the $\chi^{2}$ test with Yates's correction or

Table 2 Prevalence of damp housing and long standing illness by quartile of return of questionnaire

\begin{tabular}{|c|c|c|}
\hline Quartile & $\begin{array}{l}\text { Damp housing } \\
\text { prevalence (\%) } \\
(95 \% \text { CI) }\end{array}$ & $\begin{array}{l}\text { Long standing illness } \\
\text { prevalence (\%) } \\
(95 \% \text { CI) }\end{array}$ \\
\hline $1 \mathrm{st}$ & $\begin{array}{l}9 \cdot 7 \\
(7 \cdot 2,12 \cdot 2)\end{array}$ & $\begin{array}{l}38 \cdot 3 \\
(34 \cdot 0,42 \cdot 6)\end{array}$ \\
\hline 2nd & $\begin{array}{l}9 \cdot 0 \\
(6.5,11 \cdot 5)\end{array}$ & $\begin{array}{l}39 \cdot 1 \\
(34 \cdot 8,43 \cdot 4)\end{array}$ \\
\hline 3 rd & $\begin{array}{l}7 \cdot 2 \\
(5 \cdot 0,9 \cdot 4)\end{array}$ & $\begin{array}{l}34 \cdot 7 \\
(30 \cdot 6,38 \cdot 8)\end{array}$ \\
\hline 4th & $\begin{array}{l}9 \cdot 0 \\
(6 \cdot 5,11 \cdot 5)\end{array}$ & $\begin{array}{l}39 \cdot 4 \\
(35 \cdot 1,41 \cdot 7)\end{array}$ \\
\hline
\end{tabular}

Fisher's exact test for the comparison of two proportions, and the normal approximation to the binomial distribution for calculation of the $95 \%$ confidence intervals of the difference between two proportions. A significance level cut off of $p=0.05$ was used. At this level there is a 1 in 20 likelihood of a chance finding being classed as significant. Because approximately 50 comparisons are made in this study, two to three associations classed as significant may have occurred by chance alone.

A confidence interval approach, Tennant and Badley, ${ }^{9}$ for investigating non-response bias was used to estimate the possible effects of the prevalence of damp housing among non-responders to the survey on the likely total sample prevalence rate.

\section{Results}

RESPONSE RATE

Of the 5347 questionnaires sent out, 2353 completed questionnaires were returned. A follow up study of non-respondents to the Avon survey had suggested that a total of $17 \cdot 6 \%$ of questionnaires failed to reach the respondent because of an incorrect postal address. Although a similar follow up study was not undertaken in Worcester, the proportion of questionnaires returned to the post office as "not known at this address" was similar in both surveys. Our estimate of the true response rate to this survey, based on a $17 \cdot 6 \%$ incorrect address rate, is $\mathbf{5 2 \%}$. Comparison of the characteristics of respondents with the demographic profile of the city from the 1991 census suggests that young people and men are relatively under represented in the sample $(42.3 \%$ males in sample and $50.7 \%$ in population), as are people from the poorer electoral wards. However, all social, demographic, and geographical groups are represented among respondents.

Any analysis of a survey with this level of response must consider the effects of response bias. We have used two methods to assess the impact of response bias on our results successive responder wave analysis for time trends ${ }^{10}$ and a confidence interval approach to estimate the full sample population prevalence rate.

The returns were separated into four quartiles according to the time of their return. The prevalence of the main variables of damp housing and long standing ill health were compared across the quartiles to assess if those in damp housing or with a long standing illness were more likely to return their questionnaires sooner than others (table 2). Following the hypothesis that people who do not respond are more likely to be in poor housing and poor health, an increasing prevalence of these factors among responders over the quartiles of the response would be expected. There is, however, no apparent time trend of these variables in this study and no reason to believe that those who did not respond are any different in these main variables from those who did.

Another method of assessing any likely differences between responders and non-responders is to estimate the prevalence of damp 
housing in the non-responders and the total sample population using the confidence interval approach devised by Tennant and Badley. ${ }^{9}$ This method assumes that there is no bias between responders and non-responders. Using this method, the estimated total sample population prevalence of damp housing is $8.7 \%$ (95\% CI $8 \cdot 1,9 \cdot 3)$. This population prevalence will hold unless the true prevalence of damp housing in non-responders is outside the range of 7.4 to $10.0 \%$. This range is consistent with estimates that approximately $10 \%$ of housing within the city of Worcester is substandard (sample house condition survey 1987-88; Worcester City Council, unpublished).

CHARACTERISTICS OF THOSE IN DAMP HOUSING A total of $175(9 \%)$ respondents lived in housing which they reported as damp (damp housing). Of these, $122(71 \%)$ were female compared with $58 \%$ of all respondents. The group most at risk of living in damp housing was women aged 16 to 44 years $(12 \%)$. Five per cent of those in owner occupied property reported damp, compared with $28 \%$ of those living in council rented and $23 \%$ privately rented properties. Four per cent of people in social classes I and II compared with $18 \%$ of those in social class $\mathrm{V}$ lived in damp housing. Unemployment, single parent status, and smoking

Table 3 Prevalence of social factors among people who reported damp housing

\begin{tabular}{|c|c|c|c|}
\hline & $\begin{array}{l}\text { Damp housing } \\
\% \quad \text { (No) }\end{array}$ & $\begin{array}{l}\text { Dry housing } \\
\% \quad(\mathrm{No})\end{array}$ & $p$ value \\
\hline $\begin{array}{l}\text { Single parent } \\
\text { Unemployed seeking work } \\
\text { Unemployed with sickness/disability } \\
\text { Lone adult } \\
\text { Child in house }\end{array}$ & $\begin{array}{rr}4 \cdot 6 & (8) \\
6 \cdot 9 & (12) \\
5 \cdot 7 & (10) \\
12 \cdot 1 & (21) \\
39 \cdot 4 & (69)\end{array}$ & $\begin{array}{rr}1 \cdot 6 & (31) \\
2 \cdot 7 & (49) \\
2 \cdot 4 & (44) \\
7 \cdot 5 & (138) \\
35 \cdot 2 & (653)\end{array}$ & $\begin{array}{l}0.016 \\
0.004 \\
0.022 \\
0.051 \\
0.323\end{array}$ \\
\hline
\end{tabular}

Table 4 Prevalence of health related lifestyles among people who reported damp housing

\begin{tabular}{|c|c|c|c|}
\hline & $\begin{array}{l}\text { Damp housing } \\
\% \quad \text { (No) }\end{array}$ & $\begin{array}{l}\text { Dry housing } \\
\% \quad \text { (No) }\end{array}$ & $\begin{array}{l}\text { Difference \% } \\
(95 \% \text { CI) }\end{array}$ \\
\hline Smoking* & $38 \cdot 2(66)$ & $30 \cdot 2(547)$ & \multirow{5}{*}{$\begin{array}{c}8 \cdot 0 \\
(0 \cdot 4,15 \cdot 6) \\
7 \cdot 8 \\
(-0 \cdot 3,15 \cdot 9) \\
2 \cdot 8 \\
(-2 \cdot 8,8 \cdot 4) \\
1 \cdot 8 \\
(-5 \cdot 6,9 \cdot 2) \\
0 \cdot 1 \\
(-5 \cdot 3,5 \cdot 5)\end{array}$} \\
\hline Use of low fat milk† & $40 \cdot 0(62)$ & $47 \cdot 8(849)$ & \\
\hline Exercise 3 last week $\ddagger$ & $15 \cdot 4(27)$ & $18 \cdot 2(336)$ & \\
\hline Body mass index $>25 \S$ & $34 \cdot 2(60)$ & $32 \cdot 4(598)$ & \\
\hline Alcohol over limit & $14 \cdot 3(25)$ & $14 \cdot 4(265)$ & \\
\hline
\end{tabular}

* Prevalence not affected by age, sex, or social class adjustment.

+ Skimmed and semiskimmed milk drunk most often.

$¥$ Moderate or strenuous exercise three or more times a week.

$\ddagger$ Moderate or strenuous exercise three or more
$\S$ Ratio of weight $(\mathrm{kg})$ divided by height in $\mathrm{m}^{2}$.

\$ Ratio of weight $(\mathrm{kg})$ divided by height in $\mathrm{m}^{2}$.
I Over 14 units of alcohol a week for females and over 21 units a week for males.

Table 5 Prevalence of long standing illness in owner occupied housing; relationship with social class and damp

\begin{tabular}{|c|c|c|}
\hline Social class & $\begin{array}{l}\text { Damp housing } \\
\% \quad(\mathrm{No})\end{array}$ & $\begin{array}{l}\text { Dry housing } \\
\% \text { (No) }\end{array}$ \\
\hline $\begin{array}{l}\text { I and II } \\
\text { IIINM } \\
\text { Subtotal - I, II, and IIINM }\end{array}$ & $\begin{array}{l}52 \cdot 4(11) \\
66 \cdot 7(12) \\
59 \cdot 0(23)\end{array}$ & $\begin{array}{ll}30 \cdot 4 & (198) \\
38 \cdot 9 & (102) \\
32 \cdot 8 & (300)\end{array}$ \\
\hline $\begin{array}{l}\text { IIIM } \\
\text { IV } \\
\text { V } \\
\text { Subtotal - IIIM, IV, and V }\end{array}$ & $\begin{array}{l}42 \cdot 3(11) \\
60 \cdot 0(3) \\
100(1) \\
46 \cdot 9(15)\end{array}$ & $\begin{array}{ll}37 \cdot 0 & (140) \\
41 \cdot 3 & (45) \\
43 \cdot 9 & (25) \\
38 \cdot 6 & (210)\end{array}$ \\
\hline $\begin{array}{l}\text { Never worked } \\
\text { Total }\end{array}$ & $\begin{array}{c}100(1) \\
54 \cdot 2(39)\end{array}$ & $\begin{array}{lr}83 \cdot 3 & (5) \\
35 \cdot 2 & (515)\end{array}$ \\
\hline
\end{tabular}

were all more prevalent among people who reported damp housing (tables 3 and 4).

\section{LONG STANDING ILLNESS, DISABILITY, AND INFIRMITY}

The prevalence of longstanding illness was $36.8 \%$ among people in dry housing and $48.9 \%$ among those in damp housing (difference $12 \cdot 1 \%, 95 \%$ CI $4 \cdot 4,19 \cdot 8)$. Age, sex and social class were associated with long standing illness. None of the other social factors and health related lifestyles (including smoking) found to be significantly associated with damp housing was associated with long standing illness. After adjustment for age, sex, and social class the prevalence of long standing illness was $38 \cdot 8 \%$ in dry housing and $54.9 \%$ in damp housing (difference of $16 \cdot 1 \%, 95 \%$ CI $8 \cdot 4,23 \cdot 8$ ).

The relationship between damp housing, housing tenure, long standing illness, and social class is complex but important. Overall, people living in damp housing had a higher prevalence of long standing illness than those in dry housing irrespective of tenure. Because of the problems of small numbers created by dividing those in damp housing with a long standing illness into tenancy and social classes, the results are grouped into non-manual social classes (I, II and IINNM), manual classes (IIIM, IV, and V), and those who have never worked.

Among those in owner occupied housing, the relationship between damp housing and ill health was stronger in non-manual social classes (I, II, and IIINM) than it was in manual social groups (IIIM, IV, and V) (table 5). This social class relationship did not hold true for people living in council housing; although there was an overall relationship between damp and ill health, people in social class $\mathrm{V}$ and those who had never worked were less likely to report ill health if they lived in damp housing than if they lived in dry housing (table 6).

\section{CONDITIONS CAUSING LONG STANDING ILLNESS} AND DISABILITY AMONG PEOPLE IN DAMP HOUSING

All 19 conditions on the check list were more likely to be reported by people living in damp housing, but after adjustment for age, sex, and social class only back pain, high blood pressure, problems resulting from an injury or accident, neurological problems, migraine, and varicose veins were significantly more common in people living in damp housing. There were some important differences in the rate of reporting specific conditions between the different social groups. For example, $10 \%$ of those in damp, owner occupied housing reported chest problems compared with only $2 \%$ of those in damp council rented housing $(p=0.056)$. The average prevalence of chest problems for all respondents was $\mathbf{5 \%}$.

\section{DOSE RESPONSE RELATIONSHIP}

The prevalence of long standing illness was calculated for each of the different levels of severity of heavy condensation, mould, and 
Table 6 Prevalence of long standing illness in council rented housing; relationship with social class and damp

\begin{tabular}{|c|c|c|}
\hline Social class & $\begin{array}{l}\text { Damp housing } \\
\% \quad \text { (No) }\end{array}$ & $\begin{array}{l}\text { Dry housing } \\
\% \quad \text { (No) }\end{array}$ \\
\hline $\begin{array}{l}\text { I and II } \\
\text { IIINM } \\
\text { Subtotal - I, II, and IIINM }\end{array}$ & $\begin{array}{l}50 \cdot 0 \quad(3) \\
63 \cdot 3 \quad(7) \\
58 \cdot 8 \quad(10)\end{array}$ & $\begin{array}{l}50 \cdot 0 \quad(7) \\
59 \cdot 2(16) \\
56 \cdot 1 \quad(23)\end{array}$ \\
\hline $\begin{array}{l}\text { IIIM } \\
\text { IV } \\
\text { V } \\
\text { Subtotal - IIIM, IV, and V }\end{array}$ & $\begin{array}{ll}60 \cdot 0 & (9) \\
60 \cdot 0 & (6) \\
37 \cdot 5 & (9) \\
49 \cdot 0 & (24)\end{array}$ & $\begin{array}{l}40 \cdot 8(20) \\
30 \cdot 6(11) \\
51 \cdot 4(18) \\
40 \cdot 8(49)\end{array}$ \\
\hline $\begin{array}{l}\text { Never worked } \\
\text { Total }\end{array}$ & $\begin{array}{l}33.3 \quad(2) \\
50.0(36)\end{array}$ & $\begin{array}{ll}77 \cdot 8 & (7) \\
46 \cdot 5 & (79)\end{array}$ \\
\hline
\end{tabular}

Table 7 Prevalence of long standing illness by severity of housing condition (adjusted for age, sex, and social class)

\begin{tabular}{llll}
\hline Severity of condition & $\begin{array}{l}\text { Heavy } \\
\text { condensation } \\
(\%)\end{array}$ & $\begin{array}{l}\text { Dampness } \\
(\%)\end{array}$ & $\begin{array}{l}\text { Mould } \\
(\%)\end{array}$ \\
\hline Hardly ever/never/not very often & $35 \cdot 9$ & $36 \cdot 6$ & $35 \cdot 9$ \\
Quite often & $43 \cdot 3$ & $44 \cdot 8$ & $51 \cdot 1$ \\
Almost always & $54 \cdot 6$ & $45 \cdot 7$ & $78 \cdot 8$ \\
\hline
\end{tabular}

Table 8 Prevalence of problems in the six dimensions of the Nottingham Health Profile in relation to housing condition (adjusted for age, sex, and social class)

\begin{tabular}{|c|c|c|c|}
\hline Dimension of health & $\begin{array}{l}\text { Damp housing } \\
(\%)\end{array}$ & $\begin{array}{l}\text { Dry housing } \\
(\%)\end{array}$ & $\begin{array}{l}\text { Difference } \\
(95 \% C I)\end{array}$ \\
\hline Energy & $38 \cdot 5$ & $22 \cdot 7$ & \multirow{6}{*}{$\begin{array}{c}15 \cdot 8 \\
(8 \cdot 3,23 \cdot 3) \\
10 \cdot 1 \\
(3 \cdot 7,16 \cdot 5) \\
9 \cdot 3 \\
(1 \cdot 7,16 \cdot 9) \\
5 \cdot 6 \\
(-2 \cdot 0,13 \cdot 2) \\
3 \cdot 9 \\
(-1 \cdot 8,9 \cdot 6) \\
2 \cdot 8 \\
(-2 \cdot 6,8 \cdot 2)\end{array}$} \\
\hline Social isolation & $22 \cdot 7$ & $12 \cdot 6$ & \\
\hline Sleep & $40 \cdot 5$ & $31 \cdot 2$ & \\
\hline Emotional reactions & $39 \cdot 5$ & 33.9 & \\
\hline Physical mobility & $16 \cdot 7$ & $12 \cdot 8$ & \\
\hline Pain & $14 \cdot 4$ & $11 \cdot 6$ & \\
\hline
\end{tabular}

Table 9 Prevalence of areas of life affected by health status (adjusted for age, sex, and social class)

\begin{tabular}{lllc}
\hline Areas of life & $\begin{array}{l}\text { Damp housing } \\
(\%)\end{array}$ & $\begin{array}{l}\text { Dry housing } \\
(\%)\end{array}$ & $\begin{array}{l}\text { Difference } \\
(95 \% \text { CI })\end{array}$ \\
\hline Social life & $19 \cdot 6$ & $7 \cdot 8$ & $11 \cdot 8$ \\
Sex life & $19 \cdot 9$ & $8 \cdot 1,17 \cdot 8)$ \\
Job of work & $12 \cdot 6$ & $6 \cdot 4$ & $11 \cdot 8$ \\
Interests \& hobbies & $14 \cdot 7$ & $9 \cdot 0$ & $6 \cdot 17 \cdot 8)$ \\
Home life & $12 \cdot 3$ & $7 \cdot 7$ & $(1 \cdot 0,11 \cdot 4)$ \\
$5 \cdot 7$ & $(0 \cdot 3,11 \cdot 1)$ \\
Looking after the home & $11 \cdot 7$ & 6.9 & $(0 \cdot 4,9 \cdot 6)$ \\
$4 \cdot 8$ & $(0 \cdot 1,9 \cdot 7)$ \\
$3 \cdot 6$ & $(-2 \cdot 3,8 \cdot 5)$ \\
\hline
\end{tabular}

dampness. The greater the severity of each of these reported problems the higher the long standing illness rates (table 7 ).

NHP

People living in damp housing were significantly more likely to report problems in three of the six dimensions of the NHP (energy, sleep, and social isolation) than those in dry housing (table 8). A greater proportion of those in damp housing said that their lives, in every area except holidays, were affected by their health status (table 9). Overall, only $21.3 \%$ of those with longstanding health problems who lived in damp housing reported that their health affected their ability to look after the home.

\section{Discussion}

The response rate to the survey was disappointing, but not altogether unexpected. Antagonism towards the community charge (local tax) was very high at the time and the survey's association with the city council may have discouraged people from responding. In a postal survey which relies on accurate addresses some social groups such as students, the homeless, members of the armed forces, and those who have never worked will be under represented because of their mobility.

The low response rate makes it important to consider the effects of bias and the way in which this might have affected results. Previous surveys have shown that non-responders are less likely to have physical disabilities ${ }^{911}$ and more likely to have mental disability ${ }^{12}$ than responders. No surveys have considered whether damp housing affects response rates other than through its association with poverty.

Those residents who believed that their long standing illnesses were attributable to damp housing and who predicted the nature of the survey analysis, might have been motivated to respond to prove their point. But as the questions related to damp were widely separated in the questionnaire this would have required sophisticated reasoning.

The study relies on self reported and therefore subjective measures of both damp housing and ill health. A positive correlation between self reported housing conditions and independent objective assessments of temperature, humidity, and mould growth has been found in most ${ }^{5713}$ but not all ${ }^{14}$ of the studies where it has been looked for. None of these studies have provided details of the wording of questions used to report housing conditions, so direct comparison with our question on damp housing can not be made. The findings from this study are therefore based on the face validity of the question which has provided us with a prevalence estimate consistent with local housing condition surveys.

Self reported health status has been shown to be an accurate reflection of medically defined problems. $^{15}$

Because of the problem of multiple significance testing discussed previously, those significant findings with a $p$ value near to 0.05 are more likely to be those two or three that could be due to chance. These tests include those for associations between damp housing and smoking $(p=0.038)$, looking after the home affected by health $(p=0.04)$, home life affected by health $(p=0.036)$, and long standing ill health caused by persistent headache or migraine $(p=0.036)$.

Overall, the study identified a strong relationship between self reported damp housing and self reported ill health which could not be explained by social factors and health related lifestyles and shows a dose response relationship. Unexpectedly, the relationship among those in owner occupied houses proved stronger for those in non-manual social classes than manual. Among those in damp, council rented housing, people who classified themselves as in social class $\mathrm{V}$ or as part of a group 
who had never worked, were less likely to report ill health than those in other social groups.

This strong association between damp owner occupied housing and ill health among nonmanual social groups does not seem to have been reported before. Most studies on the effects of damp housing on health tend to concentrate on poor communities where dampness is more prevalent and may therefore have missed such an association.

Although it is possible that the relationship is causal, alternative explanations need to be considered. It may be that people who have a long standing illness have more difficulty maintaining their homes, resulting, among other things, in their houses becoming damp. This explanation is compatible with the finding that the relationship between damp and ill health is stronger among owner occupiers whose houses are not maintained by the local authority. For this mechanism to be operating, the level of disability among people with long standing illness would need to be clinically important. Our observation that only $21 \cdot 3 \%$ of those in damp housing with a long standing illness said that their health affected their ability to look after their home makes this unlikely.

A second possible mechanism is that people who are ill gravitate to the lower end of the housing spectrum where poor housing conditions are more common. This explanation should only apply to those living in rented accommodation, and is difficult to reconcile with the fact that the relationship between ill health and damp is weaker among those in social class $\mathrm{V}$ and the group who have never worked.

It is possible that the council rehousing policy plays a part in explaining the weaker association between damp housing and ill health among council tenants. The city council has, until the present crisis, been able to move those who are ill or disabled and in financial need into more suitable properties. This policy may have meant that ill council tenants were more likely to be rehoused in dry housing than ill owner occupiers. In this context, it is important that the conditions which were statistically associated with damp housing were not those we had expected, namely chest problems and arthritis. If housing officers and doctors in charge of allocating medical points also believe that chest problems and arthritis are exacerbated by damp housing they will be more likely to recommend people with these conditions for rehousing rather than those with other conditions. If the prevalences of chest problems are compared between those in damp owner occupied $(10 \%)$ and damp council rented housing $(2 \%)$ this selective rehousing theory is supported.

The validity of the findings is enhanced by the fact that it was possible to detect higher levels of ill health among people living in damp housing on two very different measures of health status (the GHS question and the NHP). It may be important, however, that the di- mensions of the NHP which were significantly higher among people in damp housing were those which tend to reflect mental rather than physical health status. Perhaps the effects of damp are felt through their effects on mental wellbeing which are partly manifested by an increased reporting of physical illness. Dampness may be acting as a marker for other housing problems, which are also strongly associated with poor mental health.

Finally, the possibility that the relationship between damp housing and ill health is causal must be seriously considered. The strength of the relationship between both measures of ill health and damp housing, the lack of effect on this relationship of adjustment for a wide range of potential confounding factors, and the clear dose response relationship would support this hypothesis to explain the relationship. For example the physical effects of damp such as high humidity and mould growth could be responsible for muscle tension causing backache, headaches, and high blood pressure. Cold and high humidity could predispose people to infection and houses which are unpleasant to live in could adversely affect mental wellbeing.

The authors thank Worcester City Council, Environmental Health Department for agreeing to further analysis and publishing of the results. Bristol University, Departmen of Epidemiology and the Department of Public Health Medicine, Worcester and District Health Authority.

1 Martin CJ, Platt SD, Hunt SM Housing conditions and ill health. $B M \mathcal{F}$ 1987;294:1125-27.

2 Stachan DP. Damp housing and childhood asthma: validation of reporting of symptoms. $B M 71988 ; 297: 1223-6$.

3 Dales RE, Zwanenburg H, Burnett R, Franklin CA. Respiratory health effects of home dampness and molds among Canadian children. Am f Epidemiol 1991;134:196203.

4 Melia RJW, Florey CV, Morris RW, et al. Childhood respiratory illness and the home environment. II: association between respiratory illness and nitrogen dioxide, temperature, and relative humidity. Int $\mathcal{f}$ Epidemiol 1982;11: 164-9.

5 Platt SD, Martin CJ, Hunt SM, Lewis CW. Damp housing, mould growth, and symptomatic health state. $B M \mathcal{F} 1989$; 298:1673-8.

6 Dales RE, Burnett R, Zwanenburg $H$. Adverse health effects among adults exposed to home dampness and molds. Am Rev Respir Dis 1991;143:505-9.

7 Hyndman SJ. Housing dampness and health amongst British Bengalis in East London. Soc Sci Med 1990;30:131-41.

8 Hunt SM, McKenna SP, McEwen J, Backett EM, Williams J, Papp E. A quantitative approach to perceived health status: a validation study. $\mathcal{f}$ Epidemiol Community Health 1980;34:281-86.

9 Tennant A, Badley EM. A confidence interval approach to investigating non-response bias and monitoring response to postal questionnaires. $\mathcal{F}$ Epidemiol Community Health 1991;45:81-85.

10 Tennant A, Badley EM. Investigating non-response bias in a survey of disablement in the community: implications for survey methodology. 7 Epidemiol Community Health 1991;45:247-250.

11 Locker D, Wiggins R, Sittampalam Y, Patrick DL. Estimating the prevalence of disability in the community: the influence of sample design and response bias. $\mathcal{F}$ Epidemiol Community Health 1981;35:208-12.

12 Cox A, Rutter M, Yule B, Quinton D. Bias resulting from missing information: Some epidemiological findings. $\mathrm{Br} \mathfrak{F}$ missing information: Some epidemiological findin

13 Wickman M, Graveson S, Nordvall SL, Pershagen G, Sundell J. Indoor viable dust-bound microfungi in relation to residential characteristics, living habits, and symptoms in atopic and control children. F Allergy Clin Immunol 1992;

14 Strachan DP, Sanders CH. Damp housing and childhood asthma; respiratory effects of indoor air temperature and relative humidity. F Epidemiol Community Health 1989;43: 7-14.

15 Warren MD. Interview surveys of handicapped people: the accuracy of statements about the underlying medical conditions. Rheumatol Rehabil 1976;15:295-302. 